INNOVATIONS IN PRIMARY CARE

\title{
Body Surface Examination Facilitated by Digital Microscopy
}

\author{
Sody A. Naimer, $M D^{1-3}$ \\ 'Department of Family Medicine, Siaal Family Medicine and \\ Primary Care Research Center, Ben-Gurion University of the \\ Negev, Beer-Sheva, Israel \\ 'Elon Moreh Clinic, Clalit Health Services, Shomron district, \\ Lev Shomron, Israel \\ ${ }^{3}$ Community Pediatric Service, Kedumim Family Health Center, \\ Clalit Health Services, Shomron district, Lev Shomron, Israel
}

Ann Fam Med 2020;18:181. https://doi.org/10.1370/afm.2472.

\section{THE INNOVATION}

Patients present daily with conditions affecting the superficial surface of the body of all somatic regions. From scalp hair, skin, and ocular structures all the way to the anal sphincter. In this regard, elusive clinical detail that is imperceptible to the naked eye may be revealed through magnification and illumination, thereby improving examination. The nascent technology of digital microscopy, or video dermoscopy, has exposed a world of visual information to the lay public for industrial and recreational purposes but has unfortunately not been applied in family medicine. I began to employ digital microscopic examination wherever it was likely to contribute more detail and assistance in reaching a definitive diagnosis.

\section{WHO \& WHERE}

We are a rural medical clinic with 3 practitioners in Lev-Shomron, Israel.

\section{HOW}

The digital microscope (DM) is shaped as a tubular structure, slightly longer than a finger. Two of the models I incorporate into my routine practice are the Dino-light digital microscope,

Conflicts of interest: author reports none.

\section{CORRESPONDING AUTHOR}

Sody A. Naimer, MD

Ben-Gurion University of the Negev

Siaal Family Medicine and Primary Care Research Center POB 653

Beer-Sheva Israel 84105

sodyna@clalit.org.il a more elaborate design with the capacity of polarized illumination, and an inexpensive camera: Genesys Logic Inc. At its front tip, the device is comprised of a central optic sensor and circumferentially set LED bulbs. A focusing ring and activating switch are situated along its body. (Supplemental Figure 1, http://www.AnnFamMed.org/content/18/2/181/suppl/DC1) The images will appear on the screen of any chosen device such as a personal computer, laptop, tablet, or cellular telephone. Following calibration, precise dimension measurements are possible. Still or video digital photography is possible with the option to transmit the images to colleagues for peer or specialist consultation.

A few examples from the many instances where the application of the DM assisted to secure the diagnosis are: (1) a painful plantar lesion underwent careful magnified needling until a minute sliver of glass was recovered, (Supplemental Figure 2, http://www.AnnFamMed.org/content/18/2/181/suppl/DC1); (2) a patient with a red eye refuted any secretions though DM examination revealed purulent discharge between the lashes; (3) a surgical wound failed to heal, until an obscure suture tail was identified with the DM and removed. The efforts to reach wellfocused images and reviewing the recordings together with the patient turn the consultation into a joint venture.

\section{LEARNING}

Colleagues and patients both are impressed by the simplicity of the procedure and the tremendous value gained by experiencing its added contribution to the doctor-patient encounter. Both adults and children have exhibited avid interest to observe video recordings of therapeutic procedures they underwent with the DM. Both generalists and specialists acquainted with this technique seem eager to adopt it into their own practice in order to improve patient care.

Key words: digital microscopy; video dermoscopy; body surface examination; magnified illumination

Submitted March 31, 2019; submitted, revised, April 19, 2019; accepted May 8, 2019.

For additional information, including supplemental materials, see it online at http://www.AnnFamMed.org/content/18/2/181/ suppI/DC1I. 